\section{REDHEAD PARASITISING THE NEST OF THE AMERICAN BITTERN}

\author{
by Spencer G. Sealy, Battleford
}

It is commonly known that the Redhead (Aythya americana) frequently desposits eggs in other ducks' nests in the manner of the parasitic Brown-headed Cowbird (Molothrus ater). These eggs (there may be one or several) are deposited in "foreign" nests presumably for the purpose of curtailing its own incubation duties. The purpose of this note is to report an unusual host selected by the Redhead for its nest parasitism.

On the evening of June 21, 1963, two miles north of Cassils, Alberta, an American Bittern (Botaums lentiginosus) was flushed from a nest containing three eggs of its own and three eggs of the Redhead. The nest was a flat platform raised only a few inches above the water in a dense cattail (Typa) marsh. A close examination of the nest showed that normal incubation was apparently progressing. On a subsequent visit on June 28, the nest was found flooded by the rising water level caused by heavy rains.

A second Bittern nest parasitized by the Redhead was found near Ranier, Alberta, by Mr. James Wolford in early June, 1965. When the nest was visited by Mr. J. P. Ryder and myself on June 19, it contained three Bittern eggs and two Redhead eggs. This nest, situated in a bulrush (Scirpus) marsh, appeared to be de-

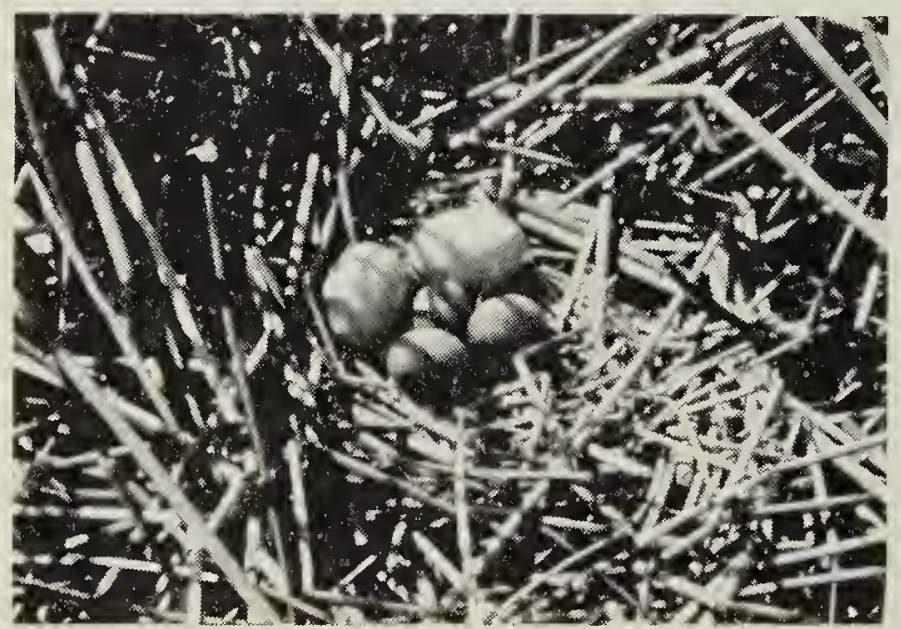

Photo by S. Sealy

Bittern nest parasitized by Redhead, Ranier, Alberta, June 19, 1965 serted for no adult was seen, the eggs were cold and two of the Bittern eggs were cracked. This latter condition possibly resulted from breakage during a nest battle between host and parasite; the Redhead, according to Weller (1959), is often aggressive and will attempt to drive a would-be host away from its nest so that it may lay eggs in the host's nest.

It is interesting to speculate on the outcome of such a host-parasite relationship when the diverse characteristics of the two species are considered. Bent (1926) reports the incubation period of the Bittern to be about 28 days whereas it is $22-24$ days in the Redhead (Bent, 1923). Synchrony in the incubation period of parasite and host is important in the evolution of a parasitic system such as this. Another consideration is that Bittern nestlings are altricial, remaining in the nest about two weeks (Bent, 1926), while Redhead young are precocial and leave the nest soon after their natal down is dry. The young Redheads would hatch first, leave the nest early and be required to fend for themselves. It would be interesting to observe the reaction of an adult Bittern to young Redheads and to see if she ceases to incubate her own still unhatched eggs. The difference in feeding habits of the two species also poses an interesting question. Hoyt (1943) reports a case where a young Starling (Sturnus vulgaris) hatched by a Pileated Woodpecker (Dryocopus pileatus) lived only a day. He attributed its death to starvation as the woodpecker's bill would "undoubtedly reach and puncture its stomach." Such a case of feeding incompatibility would also exist between the Bittern and the Redhead.

\section{LITERATURE CITED}

Bent, A. C. 1923. Life history of North American wild fowl. Part 1. U.S. Nat. Mus. Bull. 126. 244 p.

Bent, A. C. 1926. Life histories of North American marsh birds. U.S. Nat. Mus. Bull. 135. $490 \mathrm{p}$.

Hoyt, J. S. Y. 1948. Observations on nesting associates. Auk. $65: 188-196$.

Weller, M. W. 1959. Parasitic egg laying in the Redhead (Aythya americana) and other North American Anatidae. Ecol. Mono., $29: 333-365$. 